\title{
PEMANFAATAN MIKROKONTROLER ATMEGA 16 SEBAGAI PENGATUR KECEPATAN MOTOR BRUSHLESS DC
}

\author{
Abdul Majid ${ }^{(1)}$, Muhar Danus ${ }^{(2)}$ \\ ${ }^{(1,2)}$ Program Studi Teknik Elektro Fakultas Teknik Universitas Muhammadiyah Palembang \\ Email : abdulmajid3112@gmail.com
}

\begin{abstract}
Abstrak---Seiring dengan perkembangan zaman, kebutuhan sistem pengerakan listrik yang efisien, keceptan torsi yang tinggi, dan perawatan yang murah semakin meningkat. Motor brushless DC yang tersedia saat sebagian belum mampu memenuhi kebutuhan tersebut. Percepatan motor dapat di kendalikan oleh sebuah mikrokontroler tanpa harus mengubah jumlah lilitan, besar penampang, dan besar coil kumparan. Penelitian ini bertujuan memanfaatan mikrokontroler ATMega 16 pada motor brushless DC sebagai pengatur kecepatan motor diharapkan mampu untuk memenuhi kebutuhan tersebut. Osilator pada mikrokontroler memanfaatkan sistem pulse width modulation (PWM) menjadi pengatur kecepatan motor 3 phasa. Berdasarkan hasil analisis didapati bahwa semakin kecil nilai persentase PWM yang di berikan pada motor brushless DC maka semakin besar tegangan dan putaran yang di hasilkan motor.
\end{abstract}

Kata Kunci : motor brushless, mikrokontroler, PWM

\begin{abstract}
Along with the times, the needs for efficient electric scaling systems, high torque speed, and low maintenance are increasing. Brushless DC motors are available when some have not been able to meet these needs. Motor acceleration can be controlled by a microcontroller without having to change the number of turns, the size of the cross section, and the size of coil. This study aims to use the ATMega 16 microcontroller on a DC brushless motor as a motor speed regulator that is expected to be able to meet those needs. The oscillator on the microcontroller utilizes a pulse width modulation $(P W M)$ system to be a 3 phase motor speed regulator. Based on the results of the analysis, it was found that the smaller the percentage value of PWM given to the brushless DC motor, the greater the voltage and rotation produced by the motor
\end{abstract}

Keyword : Brushless, Microcontroller, PWM

\section{PENDAHULUAN}

Penggunaan motor listrik dalam aplikasi sehari-hari semakin meningkat. Motor listrik banyak digunakan dalam berbagai peralatan diantaranya air conditioning, vacum cleaner, conveyor, lemari pendingin, motor listrik dan lainnya. Motor universal dan motor direct current (DC) banyak digunakan dalam aplikasi tersebut, namun penggunaan motor DC konvensional terkadang menimbulkan masalah diakibatkan oleh penggunaan sikat. Penggantian sikat secara periodik untuk menjaga kinerja serta busur api menjadi masalah yang perlu dibahas khususnya pada motor DC [1][2]

Motor Brushless Direct Current (BLDC) menjadi alternatif pengganti motor DC [1]. Motor BLDC merupakan salah satu jenis motor yang popularitasnya mulai naik. Motor BLDC banyak digunakan dalam automotif, aerospace, kesehatan, industri, dan instrumentasi. Pengendalian motor BLDC dapat dilakukan dengan terlebih dahulu mengetahui posisi rotor untuk menentukan fase yang akan dialiri arus listrik [3]. Pendeteksian posisi dapat dilakukan dengan menggunakan sensor hall-effect. Sensor hall- 
effect umumnya berjumlah tiga buah yang terpasang pada bagian stator dan terpisah sejauh 60 derajat. Penelitian dilakukan dengan merancang alat pengatur kecepatan motor Brushless DC menggunakan mikrokontroler Atmega 16 dan sebagai penggerak motor digunakan IC Uln 2003 kanal P yang dikendalikan oleh mikrokontroler Atmega 16. Konsep pengendalian motor BLDC yang menjaga tegangan keluaran dan pengaruh perubahan duty-cycle terhadap kecepatan pada motor BLDC

\section{TINJAUAN PUSTAKA}

\section{Motor}

Stator adalah bagian motor yang diam atau statis dimana fungsinya sebagai medan putar motor untuk memberikan gaya elektromagnetik pada rotor sehingga motor dapat berputar [4] [5]. Stator pada BLDC motor hampir sama dengan stator motor listrik konvensional, hanya berbeda pada lilitannya. Stator terbuat dari tumpukan baja yang dilaminasi dan berfungsi sebagai tempat lilitan kawat. Lilitan kawat pada BLDC motor biasanya dihubungkan dengan konfigurasi bintang atau Y [1].

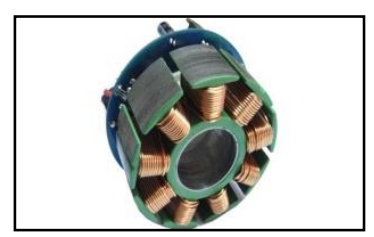

Gambar 1. Stator

Rotor adalah bagian motor yang berputar karena adanya gaya elektromagnetik dari stator [2]. Rotor pada motor BLDC berbeda dengan rotor pada motor DC konvensional yang hanya tersusun dari satu buah elektromagnet yang berada di antara brushes (sikat). Rotor terdiri dari beberapa magnet permanen yang saling direkatkan dengan epoxy, serta jumlahnya dapat di-variasikan sesuai dengan desain. Jumlah kutub magnet berbanding lurus dengan torsi motor, namun berbanding terbalik dengan rpm. Semakin banyak jumlah kutub magnet pada rotor, semakin tinggi pula torsi yang akan dihasilkan, namun konsekuensinya rpm motor akan turun [3] [6].

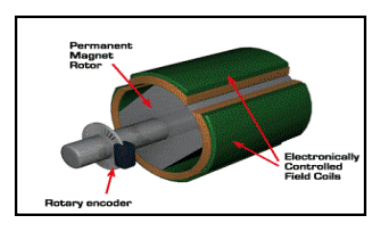

Gambar 2. Rotor BLDC Motor 
Selain itu, torsi juga dipengaruhi oleh besar kecilnya dari "densitas fluks magnet".Semakin besar densitas fluks magnet, semakin besar pula torsinya. Oleh karena itu, diperlukan material yang mempunyai sifat magnetis yang bagus untuk membuat magnet permanen dapat menghasilkan fluks magnet dengan kerapatan yang tinggi. Sebelumnya, logam ferrit dipilih karena mempunyai sifat magnetis yang cukup bagus dan juga harganya murah.Namun seiring kemajuan teknologi material, didapatkan material yang memiliki sifat magnetis yang sangat bagus seperti "Neodymium (Nd)". Logam ferrit mulai ditinggalkan karena mempunyai densitas fluks yang lebih rendah daripada Neodymium, sehingga untuk mendapatkan perbandingan "Size to Weight" yang besar, para engineer motor listrik menggunakan logam seperti Neodymium, sehingga bobot motor dapat berkurang secara drastis [1].

\section{Mikrokontroler AVR ATMega16}

Mikrokontroller merupakan suatu sistem komputer yang seluruh atau sebagian besar elemennya dikemas dalam satu chip IC, sehingga sering juga disebut dengan single chip mikrokomputer. Mikrokontroller biasa dikelompokkan dalam satu keluarga, masing-masing mikrokontroller mempunyai spesifikasi tersendiri namun masih kompatibel dalam pemrogramannya di dalam pembuatan. Pemilih microcontroler AVR ATMega 16 sebagai prosessor dari alat yang akan dibuat. (Alf and Vegard's Risc processor) AVR merupakan seri mikrokontroler CMOS 8 bit Atmel, berbasis arsitektur RISC (Reduced Instruction Set Computer) [7] [8].

Konfigurasi pin ATMega 16 dengan kemasan 40 pin DIP (Dual Inline Package) dapat terdiri dari 10 pin, fungsi dari masing-masing pin ATMega16 menurut [5].sebagai berikut :

1. VCC merupakan pin yang berfungsi sebagai masukan satu daya.

2. GND merupakan pin Ground.

3. Port A (PA.0...PA.7) merupakan pin input/ output dua arah dan pin masukan ADC.

4. Port B (PB.0...PB.7) merupakan pin input/ output dua arah dan pin fungsi khusus.

5. Port C (PC.0...PC.7) merupakan pin input/ output dua arah dan pin fungsi khusus.

6. Port D (PD.0...PD.7) merupakan pin input/ output dua arah dan pin fungsi khusus

7. RESET merupakan pin yang digunakan untuk me-reset mikrokontroler.

8. XTAL1 dan XTAL2 merupakan pin masukan clock eksternal.

9. AVCC merupakan pin masukan tegangan untuk ADC.

10. AREF merupakan pin masukan tegangan referensi ADC. 


\section{Osilator}

Pada dasarnya mikrokontroler memiliki osilator sebagai pembangkit sinyal untuk bisa beroperasi [2] [9]. Mikrokontroler ATMega 16 sendiri sudah memiliki osilator internal yaitu sebesar $8 \mathrm{Mhz}$, tetapi untuk unjuk kinerja mikronkontroler lebih cepat osilator internal tidak bisa menangani kasus dibutuhkan osilator eksternal (osilator kristal) yang nilainya lebih kurang 8 Mhz. Batas maksimum mikrokontroler ATMega hanya bisa beroprasi sampai $16 \mathrm{Mhz}$ [8], pemilih osilator krsital untuk AVR tidak boleh lebih dari $8 \mathrm{Mhz}$

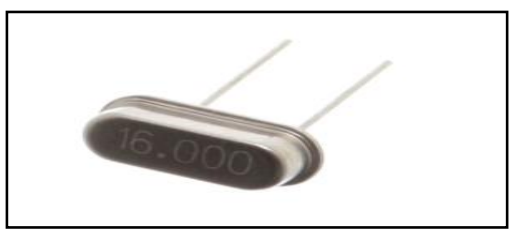

Gambar 3. Osilator Kristal

IC ULN 2003 (Gambar 4) merupakan sebuah IC dengan ciri memiliki 7 bit input, tegangan maksimum 50 Volt dan arus $500 \mathrm{~mA}$. Di dalam IC terdapat rangkaian transistor Darlington. Transistor Darlington (Gambar 5) merupakan 2 buah transistor yang dirangkai dengan konfigurasi khusus untuk mendapatkan penguatan ganda, sehingga dapat menghasilkan penguatan arus yang besar. IC ULN 2003 merupakan IC yang mempunyai 16 buah pin, pin ini berfungsi sebagai input, output dan pin untuk catu daya. Catu daya ini terdiri dari catu daya (+) dan ground. IC ULN 2003 biasa digunakan sebagai driver motor stepper maupun driver relay [9].

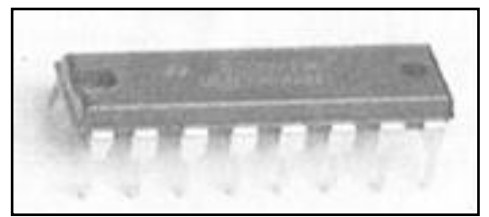

Gambar 4. Bentuk Fisik IC ULN 2003

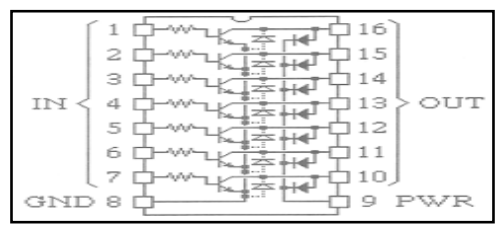

Gambar 5. Transistor Darlington Dalam IC ULN 2003 


\section{METODE PENELITIAN}

Blok diagram merupakan pengaturan kecepatan motor brushless (Gambar 6) merupakan langkah awal dalam perancangan alat. Cara kerja keseluruhan alat yang akan dibuat dapat dilihat pada diagram blok rangkaian sehingga keseluruhan diagram blok akan menghasilkan suatu sistem yang dapat difungsikan atau dapat bekerja sesuai dengan perancangan. Berikut ini adalah diagram blok dari alat Pengaturan Kecepatan Motor Brushless.

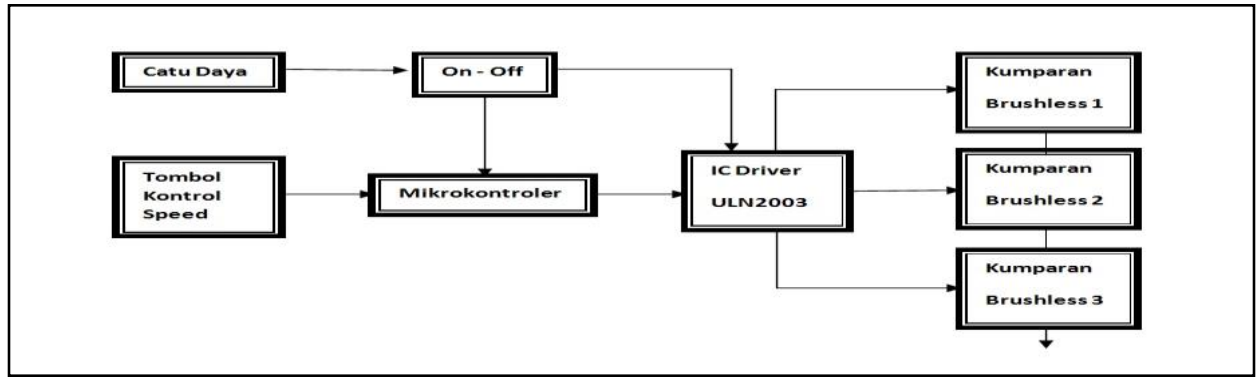

Gambar 6. Blok Diagram Pengaturan Kecepatan Motor Brushless.

Fungsi masing-masing blok dapat dijelaskan sebagai berikut:

1. Bagian catu daya, bagian ini menyuplai keperluan asupan tegangan ke bagian blok rangkaian elektronika. Jika salah satu blok tidak mendapat asupan suplai tegangan maka tidak akan bekerja.

2. Bagian on - off, sebagai saklar pemutus dan penyambung arus listrik dan tegangan.

3. Mikrokontroler merupakan tempat dimana semua proses jalannya suatu timer dan speed atau putaran akan diproses secara komputerisasi dan secara digital. Melalui port In dan Port Out digital Mikrokontroler, maka data yang dikeluarkan ke rangkaian motor brushles akan di kuatkan kembali oleh IC driver ULN 2003.

4. Tombol kontrol speed merupakan port in pada mikrokontroler untuk mengontrol kecepatan putaran pada motor dc brushless.

5. IC Driver ULN 2003 merupakan IC converse dan pada alat pengaturan kecepatan motor brushless di fungsikan sebagai penguat tegangan motor BLDC pada alat pengatur kecepatan motor.

6. Kumparan 1 sampai 3 merupakan kumparan motor brushles dimana setiap kumparan akan dialiri tegangan listrik dc secara bergantian setiap 80000-20000 milisecon. semakin kecil jeda setiap putaran maka semakin cepat putaran motor yang disebabkan semakin cepatnya gaya elektro magnetiknya pada setiap sisi motor brushelss. 


\section{Setting Mikrokontroler ATMega 16}

Langkah awal mereset semua data yang ada ketika pertama dijalankan. Setelah data berjalan maka timer internal akan hidup dan berjalan sesuai kecepatan kristal dan program yang telah di tanam untuk membangkitkan pulsa data digital. Pada kondisi ini maka data akan menunggu input tombol untuk melakukan proses perhitungan waktu jeda dan digital out yang akan dikeluarkan menuju driver dan memulai suatu pengaktifan gelombang elektromagnetik menuju kumparan motor brushless. Simulasi program menggunakan bahasa komputer AVR bertujuan untuk menguji suatu aplikasi program yang dibuat dengan pergerakan led yang ada pada layar simulasi dan dapat juga langsung dilihat pada. Bahasa komputer AVR atau IDE (Integrated Development Environment) meliputi lingkungan kerja yang terintegrasi, karena disamping tugas utamanya meng-compile kode program menjadi file hex atau bahasa mesin [8] [7], bahasa komputer AVR juga memiliki kemampuan fitur lain yang berguna sekali seperti monitoring komunikasi serial dan untuk menanamkan program yang sudah di compile ke mikrokontroler.

\section{Pulse Width Modulation (PWM)}

Pulse width modulation (PWM) adalah teknik yang digunakan dalam rancangan bangun alat pengatur kecepatan motor BLDC 3 phase ini. Dimana untuk menggontrol srikuit menggunakan metode input key (tombol) untutk mengatur suatu kecepatan yang di inginkan, dengan output digital prosesor yang bersumber dari mikrokontroler [7].

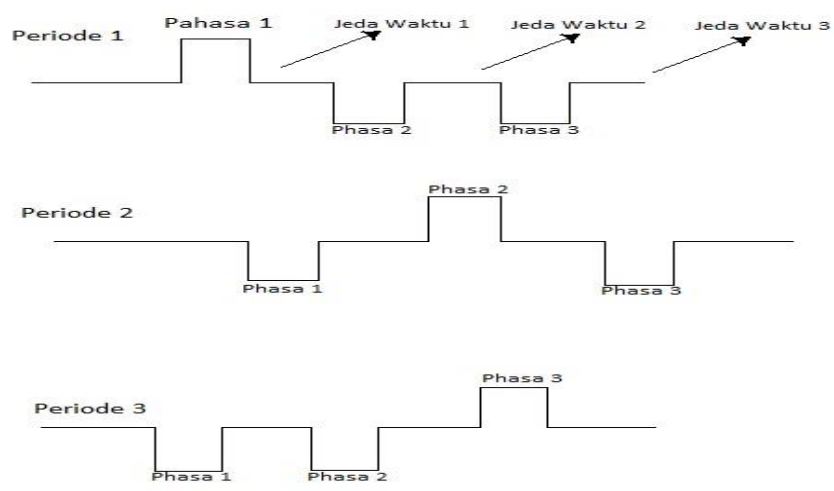

Gambar 7. PWM pada Motor 3 Phasa

PWM digunakan dalam rancang bangun alat ini adalah bersifat komunikasi untuk mengontrol kekuasaan dan konversi terhadap pembentukan medan magnet dan metode 
penggantian pergeseran medan megnet, yang melalui tahapan pengkodean signal pulsa on dan off pada setiap phase (Gambar 7). Pada priode 1 menyatakan pembentukan gaya gerak magnet dilakukan dengan cara, mengaktifkan phasa 1 dan menonaktifkan phasa 2 dan 3; pada priode ke 2, phasa 2 diaktifkan dan menonaktifkan 1 dan 3 ; dan priode ke 3 dapat mengaktifkan phasa 3 dan menonaktifkan phasa 1 dan 2 dan priode berulang ke priode 1 kembali. Aplikasi pada magnet motor 3 phasa dapat di lihat pada Gambar 8 .

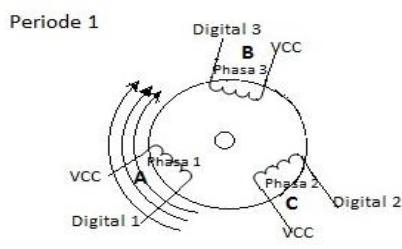

Gambar 8. Magnet Periode 1 pada Motor 3 Phasa

Metode pada alat ini menggunakan suatu metode penggantian pembentukan medan magnet, dimana setiap pergeserannya menggunakan tahapan waktu jeda untuk mengatur suatu kecepatan dari PWM tersebut [8]. Pada umumnya untuk mendapatkan suatu kecepatan diperlukan rumus luas penampang, besar kawat, jumlah lilitan, serta besarnya medan magnet.

\section{PERHITUNGAN DAN ANALISA}

Pengatur kecepatan motor brushless 3 Phasa ini pada prinsipnya setiap phasa yang terdiri dari 5 kumparan pembentuk kutub magnet, akan di aliri tegangan de secara cepat dari satu phasa ke phasa yang lain sekitar $15.000 \mu$ s. Kecepatan dari pengontrol phasa ini di tingkatkan oleh sebuah IC driver ULN 2003 yang berfungsi sebagai penguat tegangan dan penggeser phasa aktif yang sebelumnya di keluarkan tengangan minim dari sebuah mikrokontroler ATMega16. Mikrokontroler ATMega16 yang sebelumnya telah dilakukan pemrograman yang ditanam untuk menjalankan suatu operasi flip-flop 3 sudut dengan proses pengulangan 3 kali perpindahan tegangan digital.

Proses ini dilengkapi dengan tombol pengaturan kecepatan. Pemanfaatan Tombol kecepatan ini memanfaatkan jeda waktu suatu perpindahan data digital tersebut. Jeda waktu tersebut memiliki rentang waktu dari $\mu$ s - ms. 


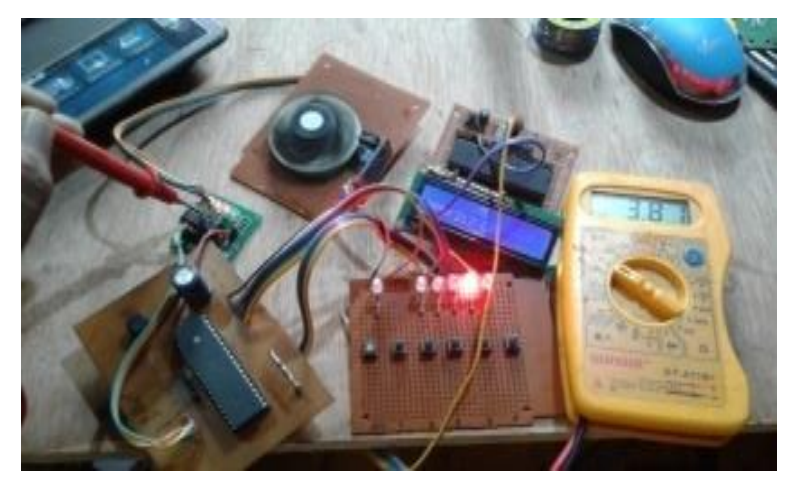

Gambar 9. Fisik Rangkaian Pengaturan Kecepatan pada Motor 3 Phasa

Pengaturan kecepatan alat ini dimana setiap percepatan di atur dalam jeda waktu, dan untuk melakukan percepatan waktu yang lebih tinggi diperlukan persingkatan jedah waktu dalam setiap pergantian phasa dan dapat di gambarkan sebagai berikut:

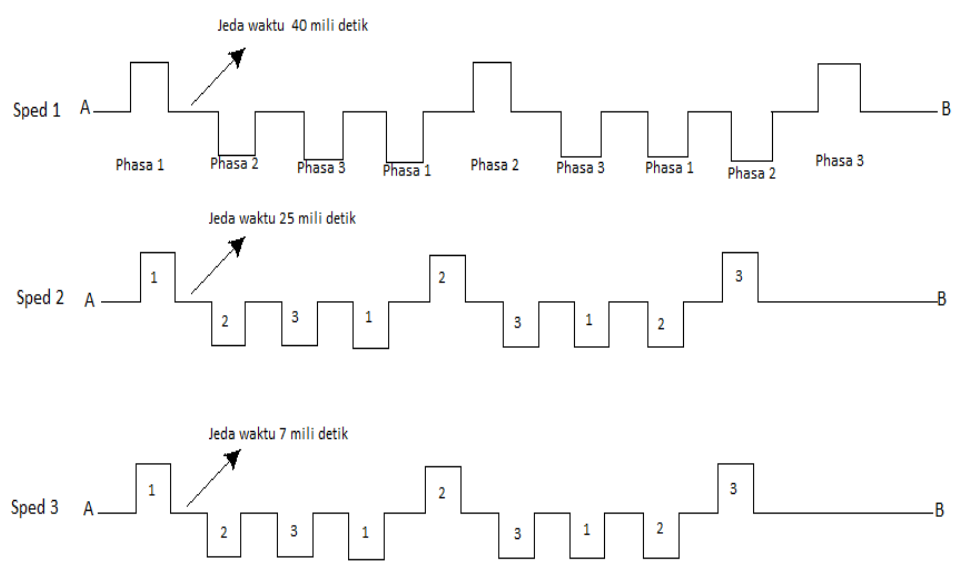

Gambar 10. Pengaturan Kecepatan Motor 3 Phasa dengan PWM

Pada Gambar 10 dapat dilihat bahwa, jika panjang gelombang dari ruas A ke B adalah 400 ms dengan titik pemberhentian berturut-turut selama $40 \mathrm{~ms}, 25 \mathrm{~ms}$ dan $7 \mathrm{~ms}$ maka, sehingga waktu tempuh dapat dihitung,

Speed $1=\frac{400}{40}=10 \mathrm{~ms} /$ putaran.

Speed $2=\frac{400}{25}=16 \mathrm{~ms} /$ putaran

Speed $3=\frac{400}{7}=57,14 \mathrm{~ms} /$ putaran 
Berdasarkan hasil perhitungan di atas, didapatkan bahwa semakin sedikit atau kecil waktu jeda maka waktu tempuh dalam sebuah putaran akan semakin tinggi. Untuk mengatur semua mode di atas dapat kita atur jedanya dapat dilakukan dengan potongan program mikrokontroler ATMega 16 menggunakan bahasa bascom sebagaimana dirancang dalam sistem perancangan programer bascom atau listing program.

Pada pengujian titik suatu beban, yaitu pada digital out yang menuju ke kumparan motor BLDC, dimana terdapat komponen penguat arus dan tegangan yang terintergrasi pada IC ULN 2003, yang didalamnya terdapat transistor Darlington (penguat ganda). Rangkaian transistor berfungsi penguat, pemotong (switching), stabilisasi tegangan, modulasi sinyal atau fungsi lainnya.

Pada pengujian titik beban mikrokontrol digilat out yang di alirin arus listrik bersumber 5 Ampere, menuju ke rangkaian penguat arus yang digunakan adalah IC ULN 2003, disana terdapat keluaran input dan output, pada keluaran input $\mathrm{A}, \mathrm{B}, \mathrm{C}, \mathrm{D}$ itu menujuh ke mikrokontroler, sedangkan keluaran output A, B, C, D itu menujuh rangkaian motor brushless 3 phasa. Hasil pengujian (Tabel 1) memuat hasil hasil pengujian yang telah dilakukan.

Tabel 1. Pengujian pada Pin pada saat dinyalakan

\begin{tabular}{|c|c|c|c|c|c|c|c|c|}
\hline Kondisi & $\begin{array}{c}\text { TP 1 } \\
\text { (Volt) }\end{array}$ & $\begin{array}{c}\text { TP 2 } \\
\text { (Volt) }\end{array}$ & $\begin{array}{c}\text { TP 3 } \\
\text { (Volt) }\end{array}$ & $\begin{array}{c}\text { TP 4 } \\
\text { (Amp) }\end{array}$ & $\begin{array}{c}\text { TP 5 } \\
\text { (Volt) }\end{array}$ & $\begin{array}{c}\text { TP 6 } \\
\text { (Volt) }\end{array}$ & $\begin{array}{c}\text { TP 7 } \\
\text { (Volt) }\end{array}$ & Keterangan \\
\hline $\begin{array}{c}\text { Saat } \\
\text { nyala }\end{array}$ & 0 & 0 & 0 & 5,0 & 0 & 0 & 0 & $\begin{array}{c}\text { TP 5, 6, 7 menyala } \\
\text { bergantian stiap }\end{array}$ \\
\hline Speed 1 & 3,70 & 3,7 & 3,70 & 4,80 & 1 & 1 & 1 & $40 \mathrm{~ms}$ \\
\hline Speed 2 & 3,78 & 3,78 & 3,78 & 4,70 & 1 & 1 & 1 & $30 \mathrm{~ms}$ \\
\hline Speed 3 & 3,80 & 3,80 & 3,80 & 4,60 & 1 & 1 & 1 & $20 \mathrm{~ms}$ \\
\hline Speed 4 & 3,81 & 3,81 & 3,81 & 4,60 & 1 & 1 & 1 & $11 \mathrm{~ms}$ \\
\hline Speed 5 & 3,83 & 3,83 & 3,83 & 4,60 & 1 & 1 & 1 & $7 \mathrm{~ms}$ \\
\hline
\end{tabular}

Kecepatan motor brushless yang diatur dengan adanya 5 tombol speed dan rata-rata kecepatan rpm motor dari 0 sampai $400 \mathrm{rpm}$, torsi yang di hasilkan dari putaran speed 1, 60 rpm; speed 2, 82 rpm; speed 3, $142 \mathrm{rpm}$; speed 4, $217 \mathrm{rpm}$; dan speed $5 \mathrm{rpm}$ 307. Nilai ini diukur dengan alat timer internal mikrokontroler yang terpasang pada rancang bangun alat pengatur kecepatan motor brushless dc menggunakan mikrokontroler atmega 16. 
Berdasarkan data diatas dapat dikatakan kecepatan putaran rpm yang di hasilkan motor, berbanding terbalik dengan perubahan waktu jedah pada motor.

Pada pengukuran speed 1 dengan pemberian nilai PWM 40\% menghasilkan tegangan motor 3,7 Volt dan rpm yang di dapat 60; sedangkan speed 2 pemberian nilai PWM 30\% menghasilkan tegangan 3,78 Volt dan rpm yang di dapat 82; sedangkan speed 3 pemberian nilai PWM 20\% menghasilkan tegangan 3,8 Volt dan rpm yang di dapat 142; sedangkan speed 4 pemberian nilai PWM 11\% menghasilkan tegangan 3,81 Volt dan rpm yang di dapat 217; dan speed 5 pemberian nilai PWM 7\% menghasilkan tegangan 3,83 Volt dan rpm yang di dapat 307, perbedaan bentuk gelombang, penyebab perbedaan tegangan dan perkecepatan di karenakan nilai PWM yang di setting dalam program bascom AVR sesuai yang diinginkan.

\section{KESIMPULAN}

Hasil dari penelitian ini dapat disimpulkan bahwa semakin kecil nilai persesntase PWM yang di berikan pada motor brushless DC maka semakin besar tegangan dan rpm yang di hasilkan motor dan sebaliknya semakin besar pemberian nilai PWM maka semakin kecil tegangan dan putaran yang dihasilkan. Percepatan motor dapat di kendalikan oleh sebuah mikrokontroler dengan memanfaatkan sistem PWM tanpa harus mengubah jumlah lilitan, besar penampang, dan besar coil kumparan.

\section{DAFTAR PUSTAKA}

[1] A. n. Husaini, "Prinsip Kerja Motor Brushless DC (BLDC Motor)," 17 September 2015. [Online]. Available: www.insinyour.com. [Diakses 15 bulan 12 2016].

[2] T. Syifa, E. Firmansyah, Pengendalian Motor DC Tanpa Sikat Sederhana dengan DSC 16-bit pada aplikasi EDF, Jurnal JNTETI, Vol. 4, No.4, 2015

[3] A. Fahrudin, R. Effendie, A.Ashfahani, Perancangan dan Implementasi Sistem Pengaturan Kecepatan Motor Arus Searah Tanpa Sikat Menggunakan Metode PIDRobust, Jurnal Teknik ITS, Vol 5 No. 2, 2016

[4] A. J. Edminister, Rangkaian Listrik, Jakarta: Erlangga, 1997

[5] Barlian. Taufik, Cekdin. Cekmas, Rangkaian Listrik, 2013

[6] M. Gussow, Dasar-Dasar Teknik Listrik, Jakarta: Erlangga, 2004.. 